\title{
Uşak İlinde Depolanmış Buğdaylarda Bulunan Zararlı ve Yararlı Böcek Türleri ve Yayginlıklarının Belirlenmesi
}

\author{
Erdal ZENGINN ${ }^{*}$, İsmail KARACA ${ }^{2}$ \\ 1Tarım ve Orman İl Müdürlüğü, 64100, Uşak \\ ${ }^{2}$ Isparta Uygulamalı Bilimler Üniversitesi, Ziraat Fakültesi, Bitki Koruma Bölümü, 32100, Isparta
}

(Alınış / Received: 21.02.2019, Kabul / Accepted: 12.09.2019, Online Yayınlanma / Published Online: 30.12.2019)

Anahtar Kelimeler Depolanmış buğday, Populasyon yoğunluğu, Yaygınlık oranı, Uşak
Özet: Türkiye ekonomisi için oldukça önemli olan buğday, depolama aşamasında bazı zararlı böcek türlerinin istilasına uğramaktadır. Dünya genelinde depolanmış ürünlerdeki böcekler tarafından sebep olunan ürün kaybı yaklaşık \%5 civarındadır. Bu çalışmayla 2016-2017 yıllarında, Uşak ili ve ilçelerindeki üretici depolarında bulunan buğday örneklerindeki böcek türleri ve bu türlerin populasyon yoğunlukları ile yaygınlık oranları belirlenmiştir. Toplam 6 ilçeden alınan 114 adet örneğin incelenmesi sonucunda, 25 farklı böcek türü saptanmış olup bu türlerden, Dienerella sp., Cephalonomia tarsalis (Ashmead), Trogoderma variabile (Ballion) ve Liposcelis decolor (Pearman)'ın Türkiye'de ilk kez buğday depolarında bulunduğu ortaya konmuştur.

\section{Determination of Pest and Natural Enemies Species and Their Distributions on Stored Wheat in Uşak Province}

\section{Keywords}

Stored wheat, Population density, Prevalence rate, Usak

\begin{abstract}
Wheat which is very important for Turkey's economy is invaded by some of the harmful insect species in the storage process. The losses caused by insects in stored products around the world is almost 5\%. With this study, it was determined the insect species, their infestation and densitiy rates in wheat stores of Uşak province and its districts in 2016-2017. As a result of the examination of 114 samples taken from 6 districts, 25 different insect species were found and among these species, Dienerella sp., Cephalonomia. Tarsalis (Ashmead), Trogoderma variabile (Ballion) and Liposcelis decolor (Pearman) were firstly detected on stored wheat in Turkey.
\end{abstract}

\section{Giriș}

Buğday, değişik coğrafyalarda yaşayan ve birbirinden farklı toplumların temel besinlerini oluşturması açısından, yetiştiriciliği yapılan diğer tarımsal ürünlere nazaran ayrı bir öneme sahiptir. Ülkemizde, buğdaydan elde edilen gidaların tüketimde birinci sırada yer alması bu önemi daha da artırmaktadır. Karbonhidrat bakımından zengin olan buğday, hem un haline getirilip ekmek ve diğer unlu mamüllerin üretiminde kullanılarak, hem de bulgur ve irmik gibi temel gıda ürünleri şeklinde günlük öğünlerimizde yerini almıştır. Buğdayın işlenmesi sırasında ortaya çıkan kepek, razmol ve kavuz gibi yan ürünler ile kırık veya düşük kaliteli buğdaylar ise yem sanayi için oldukça önemlidir. Ayrıca son ylllarda ortaya çıkan yeni ve yenilenebilir enerji kavramıla birlikte buğday, alternatif bir yakıt olan biyoetanol üretiminde de kullanılmaya başlanmıştır.
Dünya buğday üretimi 2016 yılında 220107551 ha'lık alanda yapılmış olup, toplamda 749460077 ton ürün elde edilmiştir. Bu üretimin \%19.2' si Avrupa Birliği üyesi 28 ülke tarafından gerçekleștirilirken, \%17.1'ni Çin, \%11.5'ini Hindistan, $\% 9.6$ 'sını Rusya üretmektedir [1].

Türkiye, dünya buğday ekim alanının \%3.5'ine sahiptir. Ülkemizde buğday ekim alanı; toplam işlenen tarım alanlarının yaklaşık \%33'ünü, tahıl ekili alanların ise yaklaşık \%67'sini kapsamaktadır. Ülkemizde 2016 yılında 7609868 ha'llk bir alanda buğday ekimi yapılmış ve 20600000 ton ürün elde edilmiştir [2]. Buğday üretiminde bölgeler arasında ilk sırada 7080000 ton ile İç Anadolu Bölgesi, ikinci sırada 3719000 ton ile Güneydoğu Anadolu Bölgesi ve üçüncü sırada da 2935000 ton ile Marmara Bölgesi yer almaktadır. Ege bölgesinde 2016 yılında gerçekleşen ekim alanı ise 627349 ha olmuş ve toplamda 1554734 ton ürün elde edilmiştir. Ege

*ilgili yazar: Oerdalzengin0@gmail.com 
bölgesindeki 627349 ha'lık buğday ekim alanının 364285 ha (\%58)'lık kısmı Afyonkarahisar, Kütahya ve Uşak illerinde gerçekleşmiştir [3].

Ülke ve bölge ekonomisi açısından bu kadar önemli ve bölge çiftçisinin vazgeçilmez ürünü olan buğday, depolama aşamasında birçok zararlı böcek ve akar türünün saldırısına uğramakta ve bu durum da ekonomik kayıplara sebebiyet vermektedir. Dünya genelinde depolanmış ürünlerdeki kaybın \%10 olduğu ve bu kaybın \%5'lik kısmını, böceklerin sebep olduğu kayıpların oluşturduğu belirlenmiștir [4-5].

Depolardaki böcek türlerinin ürünlerin kalite ve kantitesine verdiği doğrudan zararların yanında insan ve hayvan sağlığında alerjik reaksiyonlara sebep olan fungal toksinlerin taşınmasında da önemli rol oynadıkları tespit edilmiştir. Aspergillus ve Salmonella gibi patojenlerin çoğu depo zararlısının vücutları üzerinde bulunan kıllar ve tüyler vasıtasıyla uzak mesafelere taşınabildiği bildirilmiştir [5-6].

Bu çalışmada, Uşak ilinde çiftçi şartlarında depolanan buğdaylardaki zararlı ve yararlı böcek türlerinin durumu, bunların populasyon yoğunlukları ve yaygınlıkları incelenmiştir.

\section{Materyal ve Metot}

Çalıșmanın ana materyalini Uşak İli ve İlçelerinde bulunan üretici depolarından alınan buğday örnekleri ve örneklerden elde edilen böcek türleri oluşturmuştur.

\section{1. Örneklerin alınması}

Bu çalışma için, 2016 ve 2017 yılları Haziran-Ekim ayları arasında Merkez, Banaz, Eşme, Karahallı, Sivash ve Ulubey ilçelerinden 59 farklı lokasyondan toplam 114 örnek alınmıştır. Buğday depolayan üretici sayısının oldukça az olmasından dolayı örneklerin alınacağı yerlerin belirlenmesi bir program dahilinde yapılamamış ve rastgele seçilmiştir. Örnekler, betonarme ya da ahşap malzemeden yapılmış üretici depolarında, dökme yığın şeklinde veya çuvallar içinde muhafaza edilmekte olan buğdaylardan alınmıştır. Örnekler, depolarda yı̆̆ın olarak bulunan buğdayların 4 farklı noktasından, çuvallanmış olarak depolanan buğdaylardan ise 3 farklı çuvaldan, yüzeyden ve yaklaşı $50 \mathrm{~cm}$ derinlikten olmak üzere yaklaşı 2 kg'lık paçallar oluşturulacak şekilde alınmıştır. Daha sonra bu paçallardan 660 ml'lik kavanozlara alt örnek alınmış ve kavanozların ağızları böcek giriş çıkışını engelleyecek şekilde ince tüllerle kapatılmıştır. Üretici depolarındaki buğday yığınlarının derinliği çok fazla olmadığı için örnekler el ya da kürek yardımıyla alınmıştır. Her bir kavanozun üzerine örneğin alındığı yer ve tarih bilgisini içeren etiketler yapıştırılarak oda sıcaklığında 2 ay muhafaza edilmiştir.

\section{2. Örneklerin incelenmesi ve türlerin teşhisi}

Kavanozlarda 2 ay süreyle muhafaza edilen örnekler $2 \mathrm{~mm}$ elek gözü genişliği olan elekle elenmiş, elek altında kalan materyal beyaz bir zemin üzerine boşaltılarak yoğun ışıklı bir ortamda önce gözle daha sonra binoküler mikroskop altında incelenmiştir. Daha sonra elek üstünde kalan materyal de gözle kontrol edilmiştir. Tespit edilen böcek türleri ağız aspiratörü yardımıyla plastik kutulara taşınmıştır. Plastik kutular içine etil asetat emdirilmiş pamuk konularak canlı bireyler öldürülmüș ve böcek türleri incelemeye hazır hale getirilmiştir. Buğday örneklerinde tespit edilen larvalar oda sıcaklığında ağızları tülle kaplı plastik kavanozlarda kültüre alınarak ergin hale gelmeleri beklenmiștir.

Teşhis için hazırlanan böcek türleri stereomikroskop yardımıla incelenmiștir. İncelenen böcekler Halstead [7], Perkins[8], Hassan ve El-Hawagry [9], Rees [6], Friedman [10], Canadian Grain Commission [11], Oklahoma State University [12]'ye göre cins ve tür düzeyinde ayırımları yapılmıştır.

Alınan buğday örneklerinin incelenmesi sonucu tespit edilen her bir türe ait populasyon yoğunluk oranı ve yaygınlık oranı tespit edilmiștir. Böcek türünün örneklerde tespit edilen sayısının toplam böcek sayısına oranlanmasıyla populasyon yoğunluğu yüzde olarak bulunmuştur. Türün tespit edildiği örnek sayısının toplam alınan örnek sayısına oranlanmasıyla da her bir türe ait yaygınlık oranı hesaplanmıştır. Ayrıca her bir örnekten rastgele 100 buğday tanesi 3 tekerrür olacak şekilde seçilerek yuvarlak muntazam delikli olanlar zarar görmüș tane olarak değerlendirilmiş ve her örnek için ortalama zarar görmüș tane sayısı tespit edilmiştir

\section{Bulgular ve Tartışma}

Uşak ili üretici koşullarında depolanan buğdaylarda yapılan sürvey çalışmaları sonucunda, 4 takımdan 15 familyaya ait toplam 25 türün varlı̆̆ tespit edilmiştir. Tespiti yapılan bu türlerden 17 tanesi (\%68) Coleoptera, 4 tanesi (\%16) Hymenoptera, 2 tanesi (\%8) Lepidoptera ve 2 tanesi (\%8) de Psocoptera takımlarına aittir (Tablo 1). Schöller ve Prozell [13]'de Almanya'da tespit edilen depolanmış ürün zararlılarının 145 türünün Coleoptera takımına ait olduğunu bunu sirasiyla Lepidoptera, Psocoptera ve Hymenoptera takımlarının izlediğini bildirmişlerdir. Bu çalışmadan farklı olarak Hymenoptera takımının 4. sırada yer almasının sebebi, Almanya' da yapılan çalışmanın sadece buğdayda değil daha fazla ve daha çeşitli türdeki depolanmış ürünlerde yapılmış olmasından kaynaklandığı düşünülmektedir.

Yapılan bu çalışma sonucunda saptanan türlerden 4 tanesinin depolanmış sağlam buğday taneleriyle beslenebilen (primer) zararlı olduğu belirlenmiştir. $\mathrm{Bu}$ türler, Sitophilus granarius (L.) (Coleoptera: Curculionidae), Rhyzopertha dominica (Fabricius) 
(Coleoptera: Bostrichidae), Trogoderma granarium (Everts) (Coleoptera: Dermestidae) ve Sitotroga cerealella (Olivier) (Lepidoptera: Gelechiidae)'dir. İç karantinaya tabi olan T. granarium sadece bir örnekte tek bir birey olarak bulunmuştur. Özar ve Yücel [14]'in yaptıkları çalışmada, T. granarium Mardin ve Şanlıurfa illerindeki hububat depolarında en yaygın ve en çok karşılaşılan tür olmuştur. Bu illerin Uşak iline oranla daha sıcak bir iklim yapısına sahip olmasından dolayı bu farklılık ortaya çıkmıştır. Alınan örneklerden elde edilen Cephalonomia tarsalis (Ashmead) (Hymenoptera: Bethylidae), Lariophagus distinguendus (Förster) (Hymenoptera: Pteromalidae), Anisopteromalus calandrae (Howard) (Hymenoptera: Pteromalidae) ve Bracon hebetor (Say) (Hymenoptera: Braconidae) depo zararlılarının parazitoiti olarak tespit edilmiștir. Populasyon yoğunluğu ve yaygınlık oranı en fazla olan yararlı türler sırasıyla $L$. distinguendus ve $A$. calandrae olmuştur. Işıkber vd. [4] faydalı tür olarak Choetospilla elegans (L.) (Hymenoptera: Pteromalidae)'ın Yücel [15]'de Scenopinus fenestralis (L.) (Diptera: Scenopinidae)'in depolanmış ürünlerde varlığını bildirmişlerdir.

Tablo 1. Ușak ili ve ilçelerinde tespit edilen türler

\begin{tabular}{|l|l|l|}
\hline Takım & Familya & Tür \\
\hline Coleoptera & Curculionidae & Sitophilus granarius \\
\hline Coleoptera & Silvanidae & Oryzaphilus surinamensis \\
\hline Coleoptera & Tenebrionidae & Tribolium castaneum \\
\hline Coleoptera & Laemophloeidae & Cryptolestes ferrugineus \\
\hline Coleoptera & Laemophloeidae & Cryptolestes pusillus \\
\hline Coleoptera & Tenebrionidae & Tenebroides mauritanicus \\
\hline Coleoptera & Bostrichidae & Rhyzopertha dominica \\
\hline Coleoptera & Dermestidae & Trogoderma granarium \\
\hline Coleoptera & Dermestidae & Trogoderma variabile \\
\hline Coleoptera & Tenebrionidae & Latheticus oryzae \\
\hline Coleoptera & Ptinidae & Ptinus clavipes \\
\hline Coleoptera & Anobiidae & Stegobium paniceum \\
\hline Coleoptera & Tenebrionidae & Alphitophagus bifasciatus \\
\hline Coleoptera & Dermestidae & Anthrenus verbasci \\
\hline Coleoptera & Cryptophagidae & Cryptophagus sp. \\
\hline Coleoptera & Latridiidae & Dienerella sp. \\
\hline Coleoptera & Silvanidae & Ahasverus advena \\
\hline Psocoptera & Liposcelididae & Liposcelis bostrychophila \\
\hline Psocoptera & Liposcelididae & Liposcelis. decolor \\
\hline Lepidoptera & Gelechiidae & Sitotroga cerealella \\
\hline Lepidoptera & Pyralidae & Plodia interpunctella \\
\hline Hymenoptera & Bethylidae & Cephalonomia tarsalis \\
\hline Hymenoptera & Pteromalidae & Lariophagus distinguendus \\
\hline Hymenoptera & Pteromalidae & Anisopteromalus calandrae \\
\hline Hymenoptera & Braconidae & Bracon hebetor \\
\hline
\end{tabular}

Çalışmanın yapıldığı her iki yılda da belirlenen türlere ait populasyon yoğunluk oranları ve yaygınlık oranları sıralamasında bir değişiklik olmamış ve sonuç olarak tespit edilen toplam 3525 birey arasında populasyon yoğunluğu en fazla olan türler sirasıyla, S. granarius (1968, \%56), O. surinamensis (1006, \%28), R. dominica (196, \%6), Tribolium castaneum (Herbst) (Coleoptera: Tenebrionidae) (98, \%3) ve diğer $(257, \% 7)$ türler olduğu belirlenmiştir (Şekil 1).

Uşak il ve ilçelerinden 2016 ve 2017 yıllarında alınan toplam 114 örneğin \%44'ünde $S$. granarius türü bulunmuş ve bu tür örneklerdeki en yaygın tür olmuştur. Bu türü sırasıyla O. surinamensis (\%43), C. ferrugineus (\%13) ve T. castaneum (\%11) türleri takip etmiştir (Şekil 2).

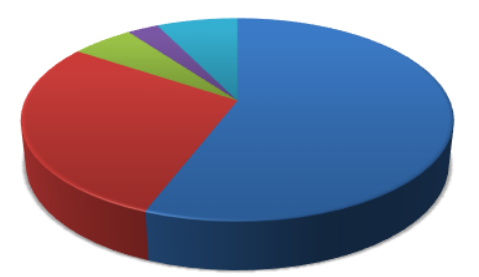

$$
\begin{array}{ll}
\square \text { S.granarius } & \mathbf{\Delta} \text { O.surinamensis } \square \text { R.dominica } \\
\square \text { T.castaneum } & \square \text { Diğer }
\end{array}
$$

Şekil 1. Türlerin populasyon yoğunluk oranları

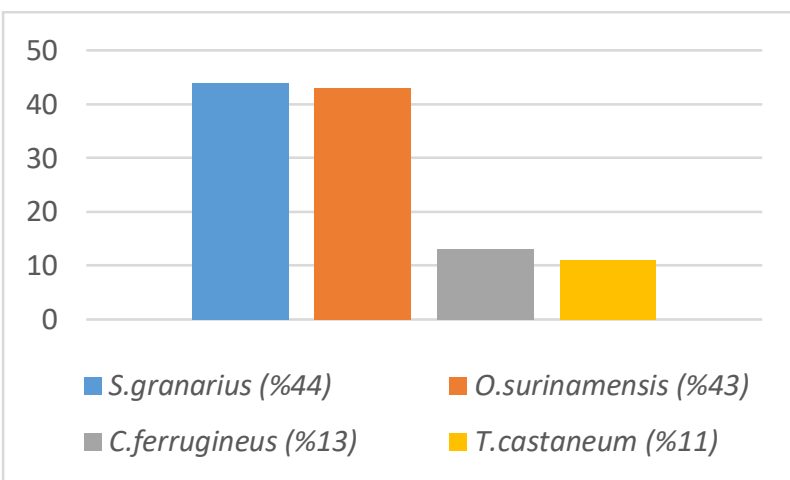

Şekil 2. Elde edilen türlerin yaygınlık oranları

Ergül vd. [16]'nin Doğu ve Güneydoğu Anadolu Bölgesi'nde yaptıkları çalışmada, bu çalışmayla benzer olarak en yaygın türler sırasıyla $S$. granarius ve $O$. surinamensis olarak tespit edilmiştir. Kiper ve Yasan [17]'ın Karadeniz Bölgesi'nde yaptıkları çalışma sonuçlarına göre, yine aynı şekilde bu çalışmayla paralel olarak en yaygın türler $O$. surinamensis ve $S$. granarius olmuștur. Ișıkber vd. [4] Kahramanmaraş ve Adıyaman illerindeki buğday depolarındaki en yaygın türlerin bu çalışmadan farklı olarak $R$. dominica ve $T$. confusum olduğunu tespit etmişlerdir. Bölgeler arasındaki iklim farklılığının ve bu çalışmaya büyük ticari siloların da dahil edilmesinden dolayı sonuçlarda değişiklik olduğu düşünülmektedir.

Örneklerin alındığı 2016 yılında yapılan incelemeler sonucunda ilçelere ait örneklerdeki ortalama böcek sayıları tespit edilmiștir (Tablo 2). En fazla ortalama böcek sayısı Merkez ilçeden alınan örneklerde tespit edilirken, en az böcek ortalaması ise Banaz ilçesinden alınan örneklerde tespit edilmiştir. Ayrıca bir örnekte tespit edilen en fazla birey sayısı 106 adetle Merkez ilçeden alınan örnekte belirlenmiştir.

Çalışma süresince 2017'de alınan örneklerde en fazla ortalama böcek sayısı Eşme ilçesinden alınan örneklerde tespit edilirken, en az böcek ortalaması ise Karahallı ilçesinden alınan örneklerde tespit 
edilmiştir. Bir örnekte bulunan en fazla birey sayısı 480 adet olarak Eşme ilçesinden alınan örnekte sayılmıștır (Tablo 3).

Tablo 2. 2016 yılında alınan örneklerde tespit edilen ortalama böcek sayıları $( \pm \mathrm{SH})$

\begin{tabular}{lcc} 
İlçe & $\begin{array}{c}\text { Ortalama Böcek } \\
\text { Sayısı }\end{array}$ & $\begin{array}{c}\text { Min.- Maks. Böcek } \\
\text { Sayısı }\end{array}$ \\
\hline Banaz & $2.4 \pm 1.18$ & $0-8$ \\
\hline Eşme & $4.4 \pm 2.88$ & $0-15$ \\
\hline Karahallı & $6.4 \pm 4.01$ & $0-35$ \\
\hline Merkez & $30.1 \pm 7.43$ & $0-106$ \\
\hline Sivaslı & $10.4 \pm 4.83$ & $0-29$ \\
\hline Ulubey & $6.0 \pm 4.51$ & $1-24$ \\
\hline
\end{tabular}

Tablo 3. 2017 yılında alınan örneklerde tespit edilen ortalama böcek sayıları $( \pm \mathrm{SH})$

\begin{tabular}{lcc}
\hline İlçe & $\begin{array}{c}\text { Ortalama Böcek } \\
\text { Sayısı }\end{array}$ & $\begin{array}{c}\text { Min.- Maks. Böcek } \\
\text { Sayısı }\end{array}$ \\
\hline Banaz & $44.5 \pm 0.73$ & $0-226$ \\
\hline Eşme & $93.0 \pm 2.26$ & $0-480$ \\
\hline Karahallı & $7.5 \pm 0.17$ & $0-61$ \\
\hline Merkez & $20.1 \pm 0.35$ & $0-84$ \\
\hline Sivaslı & $80.1 \pm 1.59$ & $0-194$ \\
\hline Ulubey & $16.8 \pm 0.40$ & $0-97$ \\
\hline
\end{tabular}

Çalışma sonucunda 2017'de alınan örneklerdeki böcek sayılarının ortalaması 2016'daki ortalamalara nazaran her ilçede daha fazla olmuştur. Bunun sebebinin 2017'de alınan örneklerin büyük bir çoğunluğunun buğday hasat tarihinden önce alınmış olması ve dolayısıyla depolardaki ürünlerin 2016 yılında hasat edilen ürünler olmasından kaynaklandığı sonucuna varılmıştır. 2016'da yapılan örneklemeler ise genellikle Temmuz ayından sonra yapıldığı ve depolarda yeni ürün olduğu için böcek sayıları düşük olmuştur.

2016 yılında alınan örneklerde tespit edilen zarar görmüş tane ortalamaları Tablo 4.'te verilmiştir. En yüksek zarar ortalaması 2.2 adet ile Merkez ilçeden alınan örneklerde belirlenirken, en düşük zarar ortalaması ise 0.1 adet ile Eşme ilçesinden alınan örneklerde tespit edilmiştir. Örneklerdeki en yüksek zarar görmüş tane ortalaması 7.60 adet ile Merkez ilçeden alınan bir örnekte bulunmuştur.

Tablo 4. 2016 yılı buğday örneklerindeki zarar ortalamaları $( \pm \mathrm{SH})$

\begin{tabular}{llcc}
\hline İlçe & $\begin{array}{c}\text { Örnek } \\
\text { Sayısı }\end{array}$ & $\begin{array}{c}\text { Ortalama } \\
\text { Zarar } \\
\text { Adet/100 } \\
\text { tane) }\end{array}$ & $\begin{array}{c}\text { Min.- Maks. } \\
\text { Ortalama Zarar } \\
\text { (Adet/100 tane) }\end{array}$ \\
\hline Banaz & 8 & $0.2 \pm 0.17$ & $0.0-1.30$ \\
\hline Eşme & 5 & $0.1 \pm 0.12$ & $0.0-0.60$ \\
\hline Karahallı & 10 & $0.4 \pm 0.33$ & $0.0-3.30$ \\
\hline Merkez & 14 & $2.2 \pm 0.60$ & $0.0-7.60$ \\
\hline Sivaslı & 7 & $0.4 \pm 0.28$ & $0.0-2.00$ \\
\hline Ulubey & 5 & $0.5 \pm 0.39$ & $0.0-2.00$ \\
\hline Toplam & 49 & $0.9 \pm 0.22$ & $0.0-7.60$ \\
\hline
\end{tabular}

2017 yılında alınan örneklerdeki en yüksek zarar miktarı 2.8 adet ile Sivaslı ilçesinden alınan örnekte tespit edilmiştir. En düşük zarar ise 0.1 adet ile Ulubey ilçesinden alınan örneklerde bulunmuștur (Tablo 5). Örneklerdeki en yüksek zarar görmüş tane ortalaması 22.60 adet ile Eşme ilçesinden alınan bir örnekte tespit edilmiştir.

Tablo 5. 2017 yılı buğday örneklerindeki zarar ortalamaları $( \pm \mathrm{SH})$

\begin{tabular}{llcc}
\hline İlçe & $\begin{array}{c}\text { Örnek } \\
\text { Sayısı }\end{array}$ & $\begin{array}{c}\text { Ortalama } \\
\text { Zarar } \\
\text { (Adet/100 } \\
\text { tane) }\end{array}$ & $\begin{array}{c}\text { Min.- Maks. } \\
\text { Ortalama Zarar } \\
\text { (Adet/100 tane) }\end{array}$ \\
\hline Banaz & 10 & $2.0 \pm 1.37$ & $0.00-12.30$ \\
\hline Eşme & 9 & $2.6 \pm 2.50$ & $0.00-22.60$ \\
\hline Karahallı & 10 & $1.8 \pm 1.83$ & $0.00-18.30$ \\
\hline Merkez & 21 & $0.3 \pm 0.14$ & $0.00-2.60$ \\
\hline Sivaslı & 9 & $2.8 \pm 1.05$ & $0.00-8.00$ \\
\hline Ulubey & 6 & $0.1 \pm 0.05$ & $0.00-0.30$ \\
\hline Toplam & 65 & $1.4 \pm 0.51$ & $0.00-22.60$ \\
\hline
\end{tabular}

2016 yılında zarar görmüş tanelerin bütün ilçelerdeki genel ortalaması 0.9 adet olurken 2017 yılında bu sayı 1.4 olmuştur. 2017 yılında Merkez ve Ulubey ilçeleri dışındaki bütün ilçelerde zarar görmüş tane ortalamaları önemli ölçüde artmıştır. Bu artışın, 2017 yılında alınan örneklerdeki ortalama böcek sayılarındaki yükselişin bir sonucu olduğu kanaatine varılmıştır. Işıkber vd. [4]'nin en yüksek zarar oranını, Adıyaman ilinden alınan bir örnekte 0.33 olarak belirlemişlerdir. Çalışmanın Adıyaman ve Kahramanmaraş illerinde, ürün sirkülasyonunun fazla olduğu ve fiziki şartların uygun olduğu, çoğunlukla büyük ticari depolarda gerçekleştirilmesi bu değerin oldukça düşük kalmasına neden olmuştur.

\section{Sonuç}

Çalışmanın yapıldığı yıllarda Uşak il ve ilçelerinden alınan toplam 114 örneğin 36 tanesinde herhangi bir böcek türüne rastlanmazken, 59 örnekte ise 3 ya da daha fazla sayıda böcek türü tespit edilmiştir. Bu sonuçlara göre, çalışmaya konu olan depoların \%51'inde üç ya da daha fazla böceğe rastlandığı için Anonim [18]'e göre bu alanlarda dolu ambar ilaçlaması yapılması gerektiği belirlenmiştir. Ancak, buğdaylarını depolayan üreticilerin, söz konusu depoların fiziki şartlarını iyileştirme noktasında çok fazla bir gayretlerinin olmadığı görülmüştür. Bunun yanında depoların büyük bir çoğunluğunda herhangi bir insektisit uygulaması da yapılmamaktadır. Zararlı yoğunluğunun arttığı durumlarda depo ilaçlaması yapmak yerine ürünün satışı yapılarak depo boşaltılmaktadır. Depoların fiziki şartlarının iyileştirilerek gerekli durumlarda ruhsatlı bir insektisitle uygulama yapılmasının sonraki dönemlerde ürün kayıplarını azaltacağı düşünülmektedir. 
Çalışma illerinde yapılan gözlemlerde, buğdaylarını depolayan bazı üreticilerin depolama sırasında böcek zararından korunmak için buğdayı incir ya da ceviz yaprağı ile katlama yaparak depoya koyduğu görülmüştür. Konu hakkında farklı çalışmaların yapılmasının faydalı olacağı kanaatine varılmıştır.

Bu çalışmayla, Dienerella sp., C. tarsalis, T. variabile ve L. decolor türlerinin Türkiye'de ilk kez depolanmış buğdaylar üzerinde bulunduğu belirlenmiștir.

Yapılan bu çalışma ile Uşak il ve ilçelerindeki buğday depolarında bulunan zararlılar, bu zararlıların populasyon yoğunlukları, yaygınlıkları ve doğal düşmanları belirlenmiş olup, elde edilen verilerin daha sonraki yıllarda bu alanda yapılacak olan çalıșmalara kaynak olacağı düşünülmektedir.

\section{Teşekkür}

$\mathrm{Bu}$ çalışma, birinci yazarın doktora tez çalışmasının bir bölümü olup 4771-D1-16 nolu proje ile Süleyman Demirel Üniversitesi BAP Koordinatörlüğü tarafından desteklenmiştir. Çalışmaya sağladığı katkılarından dolayı Kahramanmaraş Sütçü İmam Üniversitesi, Ziraat Fakültesi, Bitki Koruma Bölümü öğretim üyesi Sayın Prof. Dr. Ali Arda IŞIKBER'e teşekkür ederiz.

\section{Kaynakça}

[1] TMO, 2016. 2016 Yilı Hububat Raporu. T.C. Toprak Mahsulleri Ofisi Genel Müdürlügü̈, 206s., Ankara.

[2] Food and Agriculture Organization of the United Nations (FAO), $2018 . \quad$ Crops, http://www.fao.org/faostat/en/\#data/QC (Erişim Tarihi: 10.01.2018).

[3] Türkiye İstatistik Kurumu (TÜİK), 2018. Bitkisel Üretim İstatistikleri, https://biruni.tuik.gov.tr/medas/?kn=92\&locale =tr (Erişim Tarihi: 10.01.2018).

[4] Işıkber, A.A., Özdamar, H.Ü., Karcl, A. 2005. Kahramanmaraş ve Adiyaman İllerinde Depolanmış Buğdaylar Üzerinde Rastlanan Böcek Türleri ve Bulaşma Oranları. Kahramanmaraş Sütçü İmam Üniversitesi, Fen ve Mühendislik Dergisi, 8(1), 107-113.

[5] Mason, L., McDonough, M. 2012. Biology, Behavior, and Ecology of Stored Grain and Legume Insects. Kansas State University Agricultural Experiment Station and Cooperative Extension Service, 14p, Kansas.
[6] Rees, D. 2004. Insects of Stored Products. SBS Publishers \& Distiributors PVT. LTD., New Delhi, 181s.

[7] Halstead, D.G.H. 1973. A Revision of the Genus Silvanus Latreille (S.L.) (Coleoptera: Silvanidae). Bulletin of the British Museum, 29(2), 39-11.

[8] Perkins, J.F. 1976. Handbooks for The Identification of British Insects. Royal Entomological Society, London, 38s.

[9] Hassan, S.A., El-Hawagry, M.S.A. 2001. A Revision of the Family Scenopinidae (Diptera) from Egypt. Efflatounia, 1, 1-11.

[10] Friedman, A.L.L. 2015. The Silvanidae of Israel (Coleoptera: Cucujoidea). Israel Journal of Entomology, 44, 75-98.

[11] Canadian Grain Commission, 2017. https://www.grainscanada.gc.ca/storageentrepose/sip-irs/sfb-c-eng.ht (Erişim Tarihi: 06.12.2017).

[12] Oklahoma State University, 2017. Psocid Picture Key. http://entoplp.okstate.edu/profiles/go/psocid/ p key.html (Erişim Tarihi: 25.12.2017).

[13] Schöller, M., Prozell, S. 2014. Stored-Product Insects and Their Natural Enemies in Germany: A Species-Inventory. Integrated Protection of Stored Products, 98, 27-34.

[14] Özar, İ., Yücel, A. 1982. Güneydoğu Anadolu Bölgesi'nde Ambarlanan Hububat Ürün Zararlıları Üzerinde Survey Çalışmaları. Bitki Koruma Bülteni, 22(2), 89-98.

[15] Yücel, A. 1988. Güneydoğu Anadolu Bölgesi'nde Un Fabrikaları ve Un Değirmenlerinde Bulunan Zararlılar ve Zarar Durumları Üzerinde Ön Çalışmalar. Bitki Koruma Bülteni, 28(1-2), 5777.

[16] Ergül, C., Dörtbudak, N., Akülke, A. 1972. Doğu ve Güneydoğu Anadolu Bölgesindeki Hububat ve Mamulleri ile Bakliyat Anbar Zararlılarının Yayılışı ve Zararı Üzerinde Araştırmalar. Bitki Koruma Bülteni, 12(2),129-143.

[17] Kiper, G., Yasan, E. 1992. Karadeniz Bölgesinde Depolanmış Tahıl (buğday, arpa ve pirinç) ve Çeltik Fabrikalarında Bulunan Zararlıların Saptanması, Yoğunluk ve Yayılışları Üzerinde Araştırmalar. Tarım ve Köyişleri Bakanlığı, Zira Mücadele Araştırma Yıllığı, Ankara, 142s.

[18] TAGEM, 1995. Zirai Mücadele Teknik Talimatları. Cilt-1. Tarım ve Köyişleri Bakanlığı Koruma ve Kontrol Genel Müdürlüğü, Ankara, 291s. 